\section{ONOMÁVADIN}

Revista semestral de lingüística, filología y traducción
PONTIFICIA UNIVERSIDAD CATÓLICA DE CHILE CATOLICA DE CHILE
FACULTAD DE LETRAS

\title{
El código visual en español como lengua extranjera: aspectos semióticos $\mathbf{y}$ didácticos ${ }^{1}$
}

The visual code in Spanish as a foreign language: semiotic and didactic aspects

\author{
Dimitrinka G. Níkleva \\ Universidad de Granada \\ España
}

\author{
Andjelka Pejović \\ Universidad de Kragujevac \\ Serbia
}

\section{(c) $(\mathrm{i}) \bigodot_{\mathrm{BY}}$}

Dimitrinka G. Níkleva: Departamento de Didáctica de la Lengua y la Literatura, Universidad de Granada, España. | Correo electrónico: nikleva@ugr.es

Andjelka Pejović: Departamento de Hispanística, Universidad de Kragujevac, Serbia

| Correo electrónico: andjelkapejovic73@gmail.com 


\section{Resumen}

La presente investigación pretende concienciar en mayor grado sobre la importancia de la comunicación no verbal en la didáctica del español como lengua extranjera (ELE) y, en concreto, del código visual. Se parte de la hipótesis de que la enseñanza de estos contenidos no corresponde a una programación didáctica por niveles, sino que más bien es ocasional y arbitraria. Para llevar a cabo la investigación se elaboró un cuestionario sobre el código visual en ELE con imágenes, cuya lectura o interpretación requiere el conocimiento de múltiples códigos semióticos que actúan simultáneamente. El cuestionario fue contestado por 115 alumnos en total: 92 de origen serbio y 23 anglohablantes. Los resultados confirman la hipótesis principal, que el nivel de español no muestra relación de dependencia significativa con la mayoría de las variables estudiadas.

Palabras clave: código visual; texto; imagen; español como lengua extranjera.

\section{Abstract}

This study aims to spread greater awareness of the importance of non-verbal communication and particularly of the visual code in the teaching of Spanish as a foreign language. It is based on the hypothesis that the teaching of this content does not fit into a set syllabus structured by levels, but rather is random and arbitrary. To conduct the study, a questionnaire was drawn up on the visual code in ELE containing images whose reading or interpretation required knowledge of multiple semiotic codes which act simultaneously. The questionnaire was answered by 115 students in total: 92 of Serbian origin and 23 English speakers. The results confirm the main hypothesis: that the level of Spanish has no significant relationship of dependence with most of the variables studied.

Keywords: visual code; text; image; Spanish as a foreign language.

$1 \quad$ Este trabajo se enmarca en dos proyectos de investigación:

1) "Pan-European Task Activities for Language Learning (PETALL)", código: 530863-LLP-2012-NL-KA2-KA2MP. Programa: Lifelong Learning Programme (LLP), Unión Europea.

2) El proyecto de investigación 178014 Dinamika struktura srpskog jezika, financiado por el Ministerio de Educación, Ciencia y Desarrollo Tecnológico de la República de Serbia. 


\section{Introducción}

Esta investigación parte de la convicción de que a la comunicación no verbal todavía no se le otorga la suficiente importancia en las programaciones didácticas de idiomas extranjeros $y$, en concreto, del español como lengua extranjera (ELE). Para delimitar el objeto de este estudio hemos seleccionado solo uno de los códigos semióticos no verbales: el visual. Nos planteamos estudiar la capacidad de alumnos de ELE para interpretar correctamente mensajes o textos visuales típicos de la cultura española en función de su nivel de español.

Lógicamente, extraemos el marco teórico de esta investigación de la semiótica cultural por ser la ciencia que estudia las relaciones entre los diferentes sistemas de signos.

\section{Estudios precedentes}

\subsection{El código visual como código semió- tico y su lugar en la didáctica de lenguas extranjeras}

Para situar el tema de nuestro estudio en el ámbito de la enseñanza de idiomas extranjeros partimos del documento que marca las directrices comunes en Europa y que fue elaborado por el Consejo de Europa en 2001. Se trata del Marco común europeo de referencia para las Lenguas (en adelante MCER) (Consejo de Europa, 2002). Este amplio documento dedica un apartado demasiado corto a la comunicación no verbal y se refiere solo a tres grupos: gestos y acciones (como "señalar", "mostrar"), acciones paralingüísticas y características paratextuales. Teniendo en cuenta que Umberto Eco (1989) clasifica los códigos semióticos en dieciocho grupos y aun así no incluye los cronémicos y los de origen químico (Poyatos, 1994), consideramos que los tres grupos contemplados en el MCER son absolutamente insuficientes y que en la didáctica de las lenguas extranjeras la comunicación no verbal no recibe todavía el tratamiento que se merece por la importancia que tiene en una inte- racción oral que actualmente se considera como la quinta destreza.

Siguiendo a Umberto Eco (1989), entre las comunicaciones visuales como código semiótico se pueden distinguir varios grupos:

- señales altamente convencionalizadas (banderines navales, señales de tráfico, grados militares, etc.);

- sistemas cromáticos (el valor connotativo de los colores en las sociedades occidentales: blanco - boda, negro - luto, rojo - revolución, etc.; se incluyen también los intentos poéticos de asociar algunas sinestesias a determinados colores);

- vestuario (divisas militares; hábitos y ornamentos eclesiásticos);

- sistemas verbo-visuales (cine, televisión, publicidad, cómics, mapas geográficos y topográficos...);

- códigos icónicos (por ejemplo, los empleados en las guías turísticas: cuchillo, tenedor, estrellas de los hoteles).

En nuestra opinión, hay que programar la enseñanza de la comunicación no verbal en el ámbito de idiomas extranjeros y no dejarla a la arbitrariedad o las ocurrencias de un profesor en concreto. En el caso que nos ocupa en esta investigación -el código visual-se deben incluir todos los subgrupos señalados por Umberto Eco y seguir ampliando según lo que se considere representativo para cada lengua y cultura. Lógicamente, programar significa diseñar todos los componentes curriculares (competencias, objetivos, contenidos, metodología y criterios de evaluación) para cada nivel de Aı a C2.

\subsection{La imagen como texto y como sím- bolo}

Tradicionalmente se entiende por texto toda emisión hablada o escrita, de cualquier longitud, que tenga unidad, clausura y autonomía. Con la Escuela de Tartu pasa a considerarse un conjun- 
to sígnico coherente, o sea, cualquier comunicación en un determinado sistema sígnico. Actualmente, la Lingüística del Texto lo considera como una unidad básicamente comunicativa (Níkleva, 2013). Por tanto, son textos una imagen, un cuadro, una pieza musical, una ceremonia, etc.

A continuación nos vamos a centrar en la imagen como texto visual y como símbolo. La imagen se puede explicar con las teorías de la iconicidad y con el estudio analítico de sus connotaciones expresivas, culturalmente condicionadas. El sentido figurativo de una imagen se descodifica en un determinado contexto cultural, es decir, se necesitan claves culturales para su lectura e interpretación. Tal como nos recuerda Zecchetto (2002: 180), "mientras el significante y el significado de la imagen son elementos sincrónicos, las significaciones y los sentidos son de carácter diacrónico. [...] El factor diacrónico al desplegarse a lo largo de la historia, necesariamente es también cultural".

En este estudio nos referimos solo a las imágenes que son signos icónicos, o sea, hechas de manera indirecta y sígnica. Hay que recordar que en el campo de la semiótica el iconismo se concibe como una categoría comunicativa. Las imágenes se conciben como signos, pero también como productos sociales. En palabras de Zecchetto (2002: 178) podemos considerarlas como "textos o discursos sociales en circulación" que abundan en todos los medios de comunicación como televisión, Internet, publicidad, cine, prensa escrita, etc.

Muchas de las imágenes son símbolos que por su parte funcionan como "mediador entre la sincronía del texto y la memoria de la cultura” (Lotman, 2003 [1987]: 1). Además, el símbolo contiene siempre algo arcaico; no corresponde a una sola etapa sincrónica de la cultura, sino que traspasa esta etapa verticalmente, o sea, diacrónicamente. Por ello, los símbolos se convierten en uno de los componentes más estables del continuum cultural y funcionan como mecanismo de la memoria colectiva.
Fue Saussure quien contrapuso los símbolos a los signos convencionales y destacó, además, la presencia de un elemento icónico en los símbolos, o sea, una semejanza entre el plano de la expresión y el del contenido. Por ello afirmó "que la balanza puede ser un símbolo de la justicia, puesto que contiene icónicamente la idea de equilibrio, pero un carretón, no" (Lotman, 2003 [1987]: 1).

Las imágenes se consideran textos o discursos visuales que se pueden estudiar usando un sistema de reglas o código teórico como instrumento de análisis distinto de los códigos lingüísticos (Zecchetto, 2002). En la semiótica discursiva el código se concibe como "el conjunto de operaciones de producción de sentido en el interior de una materia significante dada" (Verón, 1987: 122). Desarrollando la misma idea, en palabras de Zecchetto (2002: 178):

Según esta concepción los textos visuales generan sentido, porque en ellos se da una combinación de elementos o segmentos, cuyo resultado unitario y global es precisamente el sentido, el cual a su vez es tal, porque hay gente que así lo interpreta. Desde este punto de vista, el código se asemeja a una entidad lógica que sirve para dilucidar el funcionamiento del texto-imagen [...] Hablar del sentido de algo quiere decir, en primer lugar, referirse a las significaciones que tienen las expresiones culturales, los signos y los textos o discursos en circulación.

Los que hacen diferencia entre texto y discurso atribuyen al último las condiciones de producción y el contexto del proceso social. Es decir, el texto es un producto fijo y estático; es el discurso sin las condiciones de producción y del proceso social. Por consiguiente, consideran la imagen como discurso visual.

La conformación de la semiótica como ciencia, y más concretamente de la semiótica de la cultura, introdujo cambios fundamentales en el concepto de texto. Las definiciones iniciales lo calificaban como un enunciado en cualquier lenguaje que tuviera unidad de sentido indi- 
visible. Más tarde se formuló la idea de que el mensaje debe estar codificado, como mínimo, dos veces para que se considere texto (Lotman, 2003 [1981]: 1)

En la siguiente etapa adquirieron especial importancia "aquellos casos en que se unían textos en lenguajes esencialmente diferentes; por ejemplo, una fórmula verbal y un gesto ritual. El texto de segundo orden que se obtenía como resultado encerraba, dispuestos en un solo nivel jerárquico, subtextos en lenguajes diversos y no deducibles uno del otro" (Lotman, 2003 [1981]: 2). Empezaron a considerarse como textos el ritual, la ceremonia, el teatro, etc. Estas nuevas dimensiones del concepto trajeron "complejos problemas de recodificación, equivalencia, cambios en los puntos de vista y combinación de diferentes 'voces' en un único todo textual” (Lotman, 2003 [1981]: 2). Es el caso de los textos artísticos:

El paso siguiente desde el punto de vista heurístico es la aparición de los textos artísticos. Al ser reexpuesto en el lenguaje de un arte dado, el material multivocal adquiere una unidad complementaria. Así, la conversión del ritual en un ballet se acompaña de la traducción de todos los subtextos diversamente estructurados al lenguaje de la danza. Mediante el lenguaje de la danza se transmiten gestos, actos, palabras y gritos, y las propias danzas, que, cuando esto ocurre, se 'duplican' semióticamente. La multiestructuralidad se conserva, pero está como empaquetada en la envoltura multiestructural del mensaje en el lenguaje del arte dado. Esto es particularmente visible en la especificidad genérica de la novela, cuya envoltura —un mensaje en un lenguaje natural- oculta una controversia extraordinariamente compleja y contradictoria de diferentes mundos semióticos (Lotman, 2003 [1981]: 2).

Conviene considerar las relaciones que pueden surgir entre el texto artístico y su título. Estas relaciones pueden ser de tipo metafórico (en el caso de sustitución o equivalencia) o metonímico (en el caso de representar una parte del todo). Por una parte, el texto y el título pueden considerarse como dos textos independientes dispuestos en diversos niveles de la jerarquía 'texto-metatexto'. Por otra, pueden considerarse como dos subtextos de un único texto. El título puede referirse al texto que él designa con arreglo al principio de la metáfora o al de la metonimia. Puede estar realizado con ayuda de palabras del lenguaje primario, elevadas al rango de metatexto, o con ayuda de palabras de un metalenguaje, etc. Como resultado, entre el título y el texto que él designa surgen complejas corrientes de sentido que generan un nuevo mensaje (Lotman, 2003 [1981]: 5).

Hemos destacado las posibles relaciones entre el texto artístico y su título por la imagen del cuadro "Las calabazas" que hemos incluido en nuestro cuestionario y por considerar que la clave de interpretación está en el título (ver anexo). Se necesita dominar los dos códigos semióticos que actúan simultáneamente -el pictórico y el lingüístico-, o sea, hay que conocer la locución dar calabazas para interpretar el cuadro (Níkleva, 2013).

Las relaciones de intertextualidad entre lengua y artes (Níkleva, 2013) se manifiestan en varias de las imágenes incluidas en el cuestionario de esta investigación.

\section{Objetivos e hipótesis de la investiga- ción}

En la etapa inicial de la investigación formulamos como objetivo general estudiar la capacidad de alumnos de ELE para interpretar correctamente mensajes o textos visuales típicos para la cultura española. Para ello nos marcamos los siguientes objetivos específicos:

1) Seleccionar mensajes o textos visuales representativos para la cultura española y estudiar la capacidad de su lectura por parte de los alumnos de ELE, participantes en la investigación.

2) Ofrecer a los alumnos textos visuales para su lectura e interpretación. 
3) Estudiar la relación entre el nivel de español de los alumnos y la capacidad de lectura de textos visuales.

Formulamos las siguientes hipótesis para nuestro estudio:

1) El conocimiento del código visual no muestra relación de dependencia significativa con el nivel del español.

2) Los niveles avanzados de ELE no garantizan la lectura correcta de los textos visuales en el cuestionario.

3) Los alumnos que conocen la locución dar calabazas la usarán en la interpretación del cuadro "Las calabazas".

4) Los alumnos anglohablantes aplicarán el conocimiento del sustantivo bookworm en la interpretación de la imagen del "gusano de libros” e intentarán buscar su equivalente en español.

\section{Metodología}

A continuación presentamos el diseño de la investigación: participantes, instrumentos, métodos, análisis y discusión de los resultados.

\subsection{Participantes}

La realización de la investigación fue planteada principalmente con estudiantes de filología española en Serbia. Aun así se han incluido algunos alumnos anglohablantes para poder comparar los resultados, según la nacionalidad, entre otras variables.

En la investigación han participado 115 alumnos en total del español como lengua extranjera. Entre ellos, 92 estudian filología española ( $2^{\circ}$ y $4^{\circ}$ curso) en la Universidad de Kragujevac y en la Universidad de Belgrado en Serbia. Los otros 23 sujetos son anglohablantes (22 de Estados Unidos y 1 alumno del Reino Unido) y estudian español como lengua extranjera en el Centro de Lenguas Modernas de la Universidad de Granada (España) en grupos de nivel B1 y B2.
La edad de los participantes oscila entre 20 y 30 años. La moda y la mediana coinciden y son de 22 años (35,7\%). En cuanto al sexo, predominan las mujeres con un 92,2\% frente a un $7,8 \%$ para los hombres.

Los que estudian filología española, lingüística o español como titulación principal representan el $84,3 \%$ de los sujetos.

\subsection{Instrumento de la investigación}

El instrumento de la investigación consiste en un cuestionario compuesto por 19 preguntas (se puede consultar en el anexo) en el que se combinan preguntas cerradas y abiertas, por lo que hemos obtenido datos cuantitativos y cualitativos.

El cuestionario fue respondido de forma anónima durante el curso 2012/2013 por los alumnos serbios y en octubre de 2013 por los alumnos anglohablantes en el Centro de Lenguas Modernas en Granada.

\subsection{Métodos de análisis}

Para llevar a cabo la investigación hemos aplicado una metodología mixta - cuantitativa y cualitativa - en la que predomina el análisis estadístico cuantitativo, realizado con el programa SPSS 21. Las preguntas abiertas nos han permitido obtener también datos cualitativos. Sus respuestas fueron categorizadas posteriormente.

Se realizó el análisis descriptivo de las variables mediante tablas de frecuencia. Para el estudio de la relación entre variables cualitativas se han empleado tablas de contingencia y contrastes de independencia mediante el estadístico chi-cuadrado. Asimismo, se aplicó la prueba exacta de Fisher. Se utilizó un alfa del 5\% para evaluar la significación de los contrastes. En los casos donde los contrastes fueron significativos se midió la fuerza de asociación mediante el coeficiente $V$ de Cramer. 


\section{Análisis y discusión de los resultados}

Para el estudio de los datos del cuestionario hemos aplicado dos tipos de análisis: el descriptivo para obtener las frecuencias de cada respuesta y el inferencial para estudiar la relación de dependencia significativa entre las distintas variables.

\subsection{Resultados del análisis descriptivo}

Entre los resultados del análisis descriptivo, destacaremos las frecuencias de algunas respuestas. Tenemos que advertir que hay un alto porcentaje de preguntas no contestadas. Parece que los alumnos han preferido no contestar en los casos de considerar que no saben la respuesta.

Los alumnos demuestran alguna dificultad en determinar su nivel de español. Llama la atención que los alumnos de $2^{\circ}$ curso de Filología española en Serbia, que llevan dos años estudiando español en la Facultad, consideran que tienen niveles muy dispares entre $A 2, B 1$ y B2. Esto se debe a que algunos de ellos han estudiado español en la etapa de Educación Secundaria con dos horas lectivas por semana, otros tuvieron el español como primera lengua extranjera en el Liceo de Filología en Belgrado con cinco horas por semana. La moda del nivel de español entre los sujetos participantes es $\mathrm{C}$, es decir, un nivel avanzado, según su opinión, aunque su profesora considera que ni siquiera los alumnos de $4^{\circ}$ de Filología española tienen un nivel de Cı. En la tabla 1 resumimos los datos del nivel, según las respuestas de los alumnos.

Los participantes en la investigación llevan entre 2 y 14 años estudiando español. La moda es de cuatro años. El 87,8\% ha estudiado el espa- ñol solo en su país de origen. El 51,3\% del total nunca ha realizado una estancia en España o en otro país de habla hispana. Aquí debemos advertir que curiosamente muchos de los alumnos anglohablantes (9 de los 23) que han contestado el cuestionario, encontrándose en España, afirman que nunca han estado en España (I alumno no ha contestado esta pregunta). El $40 \%$ de ellos afirma que ha hecho una estancia de hasta 3 meses.

En el cuestionario se ofrece varios textos visuales que representan al ratoncito Pérez, al cobrador del frac, la letra de un villancico, un cuadro y una escultura vegetal, cuya descodificación requiere el conocimiento de dos códigos —el lingüístico y el pictórico o el lingüístico y el escultórico- para los últimos dos casos.

La pregunta 10 es sobre el cuadro "Las calabazas" de Ignacio Pinazo y pretende observar si los alumnos aplican la locución dar calabazas para interpretar el cuadro (ver anexo, pregunta 10). La respuesta era libre, pero hemos agrupado los resultados en nuestro análisis como verdadero o falso. La gran mayoría interpreta que se trata de una pareja enamorada, de un amor prohibido, normalmente por los padres de la chica. Una alumna estadounidense ni siquiera ve al hombre como hombre, sino como una mujer fuera de la casa que quiere hablar con su amiga dentro de la casa. Otros ven relaciones normales de vecinos o de compra-venta de calabazas que crecen en la casa, etc. Solo un 7\% de los sujetos ha dado una respuesta correcta que contempla la locución dar calabazas frente a un $87 \%$ que ha elegido una respuesta equivocada. Un $6,1 \%$ no ha contestado la pregunta. A continuación en el cuestionario se plantean otras tres preguntas relacionadas: si el alumno conoce la expresión

\section{TABLA 1}

Pregunta 6. Nivel de español

\begin{tabular}{c|c|c|c|c|c|c|c} 
NIVEL & A1 & A2 & B1 & B2 & $\mathbf{C}_{1}$ & $\mathbf{C}_{2}$ & NO CONTESTA O NO SABE \\
\hline$\%$ & $0,9 \%$ & $2,6 \%$ & $13 \%$ & $28,7 \%$ & $35,7 \%$ & $1,7 \%$ & $15,7 \%$ \\
\hline
\end{tabular}


idiomática dar calabazas, qué significa y a quién o a qué debe su conocimiento. El 63,5\% afirma que conoce esta unidad fraseológica. Sin embargo, solo un $36,5 \%$ da una respuesta correcta frente a un $24,3 \%$ de respuestas equivocadas y un $39,1 \%$ de pregunta no contestada. Un porcentaje alto $(32,2 \%)$ no ha contestado la pregunta de qué conoce la locución. La moda de esta respuesta señala "un profesor de español” (43,5\%).

Un 52,2\% de los alumnos afirma conocer al ratoncito Pérez, pero solo el $48,7 \%$ sabe a qué se dedica. El 36,5\% da una respuesta equivocada sobre lo que hace el ratoncito Pérez en la imagen ofrecida en el cuestionario. Un 49,6\% afirma que en su cultura existe un personaje parecido. Sin embargo, sorprende el gran número de sujetos que da respuestas equivocadas como Tom, Jerry, Santa Claus, San Nicolás, etc. Algunos pocos alumnos saben que en la cultura anglosajona el personaje parecido es el hada de los dientes, igual que en la cultura serbia, Zubic Vila ('el hada del dientecito'). Han sido muchos los alumnos (21) que no han contestado esta pregunta. Llama la atención que entre los 23 alumnos anglohablantes solo dos contestan que el personaje análogo en su cultura es el hada de los dientes.

El cuestionario plantea una pregunta sobre el cobrador del frac y se ofrecen dos imágenes. La respuesta correcta "visita a los morosos" ha sido elegida por un $27 \%$ de los alumnos. La respuesta más frecuente $(37,4 \%)$ ha sido "es un sastre y visita a sus clientes". Un 8,7\% no ha contestado esta pregunta. Presentamos todos los resultados (por orden descendente de frecuencia) en la tabla 2.

La pregunta 15 combina el código visual y el musical, ya que para su respuesta correcta se necesita conocer el famoso villancico "Pero mira cómo beben los peces en el río...”. Los resultados indican que solo un $20 \%$ conoce el villancico frente a un $51,3 \%$ que no lo conoce y un $28,7 \%$ que no ha contestado la pregunta.

Las últimas dos preguntas del cuestionario tienen que ver con la locución ratón de biblio-

\section{TABLA 2}

P13. ¿Adónde va el cobrador del frac?

\begin{tabular}{lc}
\multicolumn{1}{c|}{ RESPUESTA } & PORCENTAJE \\
\hline Es un sastre y visita a sus clientes & $37,4 \%$ \\
\hline Visita a los morosos & $27 \%$ \\
\hline Otro & $14,8 \%$ \\
\hline Es acompañante & $6,1 \%$ \\
\hline Va a un concierto & $4,3 \%$ \\
\hline Va a una cena & $1,7 \%$ \\
\hline Perdidos & $8,7 \%$ \\
\hline
\end{tabular}

teca. Es cierto que la penúltima pregunta necesita el conocimiento de su equivalente inglés, bookworm, pero nos ha dado la oportunidad de comprobar si los anglohablantes o los alumnos serbios que lo conocen en inglés han sabido aplicar la misma idea en español. Los resultados indican que $85,9 \%$ de los alumnos han dado una respuesta incorrecta para el bookworm frente a un 14,1 que han contestado correctamente. Para la última pregunta (Qué se pondría delante de una biblioteca en España, usando la idea de la imagen del bookworm), solo un 1,7\% da la respuesta correcta (ratón de biblioteca) frente a un $69,6 \%$ con respuestas equivocadas (como "un toro leyendo", "un toro leyendo El Quijote”, etc.) y un $28,7 \%$ sin contestar.

\subsection{Resultados del análisis inferencial}

Hemos aplicado también el análisis inferencial para determinar entre qué variables de nuestra investigación existe una relación de dependencia. Quizás lo más preocupante de los resultados obtenidos haya sido que el nivel de español no muestra relación de dependencia significativa con la mayoría de las variables estudiadas. Por ejemplo, no fue significativa la asociación entre el nivel de español y la interpretación del cuadro "Las calabazas" o el conocimiento del significado de dar calabazas. Tampoco influye en la interpretación de la dedicatoria del libro que 
contiene la letra de un villancico. Por otra parte, sí se confirmó una relación significativa entre el nivel de español y el conocimiento del ratoncito Pérez (tabla 3).

Los demás resultados confirman una relación de dependencia entre la lengua nativa (o la nacionalidad) y la interpretación de la escultura vegetal del bookworm; también entre el conocimiento del bookworm y el ratón de biblioteca. Curiosamente, se da un grado bajo de dependencia entre el conocimiento de dar calabazas y la interpretación del cuadro "Las calabazas".

El hecho de haber estudiado el español solo en el país de origen o de haber realizado una estancia en España o en otro país de habla hispana no muestra relación de dependencia significativa con el conocimiento de la locución ratón de biblioteca. En la tabla 4 presentamos los resultados de la pregunta 18 sobre el bookworm, según la nacionalidad.

En cuanto a la última pregunta, cuya respuesta correcta sería "ratón de biblioteca" y debería resultar más fácil para todos los anglohablantes, además de para cualquier sujeto que conozca la expresión en inglés bookworm, sorprendentemente las únicas respuestas correctas fueron de dos alumnos serbios (tabla 5).

\section{TABLA 3}

La relación de dependencia entre variables

\begin{tabular}{|c|c|c|c|c|c|c|}
\hline VARIABLES & $\underset{X^{2}}{\text { CHI-CUADRADO }}$ & $\begin{array}{l}\text { GRADO DE } \\
\text { LIBERTAD }\end{array}$ & $\begin{array}{l}\text { P VALOR DEL } \\
\text { CHI-CUADRADO }\end{array}$ & $\begin{array}{l}\text { TEST EXACTO } \\
\text { DE FISHER }\end{array}$ & $\begin{array}{l}\text { V DE } \\
\text { CRAMER }\end{array}$ & $\begin{array}{c}\text { GRADO DE } \\
\text { DEPENDENCIA }\end{array}$ \\
\hline $\begin{array}{l}\text { Nivel de español y } \\
\text { ratoncito Pérez }\end{array}$ & 36,212 & 6 &, 000 &, 000 & 608 & medio-alto \\
\hline $\begin{array}{l}\text { Nacionalidad y } \\
\text { bookworm }\end{array}$ & 11,555 & 2 &, 003 &, 003 &, 342 & medio-bajo \\
\hline $\begin{array}{l}\text { Lengua nativa y } \\
\text { bookworm }\end{array}$ & 10,513 & 1 &, 003 &, 003 &, 326 & medio-bajo \\
\hline $\begin{array}{l}\text { Conocer dar } \\
\text { calabazas y el cuadro } \\
\text { "Las calabazas" }\end{array}$ & 4,833 & 1 &, 049 &, 049 &, 213 & bajo \\
\hline $\begin{array}{l}\text { Bookworm y ratón } \\
\text { de biblioteca }\end{array}$ & 14,158 & 1 & 015 & 015 & ,423 & medio \\
\hline
\end{tabular}

\section{TABLA 4}

Respuesta sobre el bookworm, según la nacionalidad

\begin{tabular}{lcc} 
NACIONALIDAD & VERDADERO & FALSO \\
Serbia & $\begin{array}{c}7,9 \% \\
\text { (6 alumnos) }\end{array}$ & $\begin{array}{c}92,1 \% \\
\text { (70 alumnos) }\end{array}$ \\
\hline Estados Unidos & $\begin{array}{c}36,4 \% \\
\text { (8 alumnos) }\end{array}$ & $\begin{array}{c}63,6 \% \\
\text { (14 alumnos) }\end{array}$ \\
\hline Reino Unido & $\begin{array}{c}\text { 0 } \% \\
\text { (0 alumnos) }\end{array}$ & $\begin{array}{c}100 \% \\
\text { (1 alumno) }\end{array}$ \\
\hline
\end{tabular}

\section{TABLA 5}

Tabla de contingencia para las variables nacionalidad y ratón de biblioteca (pregunta 19)

\begin{tabular}{l|c|c|c}
\multirow{2}{*}{ NACIONALIDAD } & \multicolumn{2}{|c|}{$\begin{array}{c}\text { RATÓN DE BIBLIOTECA } \\
\text { BOOKWORM }\end{array}$} & \multirow{2}{*}{ TOTAL } \\
\cline { 2 - 3 } & VERDADERO & FALSO & \\
\hline Serbia & 2 & 59 & 61 \\
\hline Reino Unido & 0 & 1 & 1 \\
\hline Estados Unidos & 0 & 20 & 20 \\
\hline Total & 2 & 80 & 82 \\
\hline
\end{tabular}

Los resultados obtenidos significan que los conocimientos del código visual no corresponden a una programación didáctica por niveles de Aı a C2. Parece que el aprendizaje de este código 
es ocasional, arbitrario y depende del profesor concreto y de sus preferencias individuales, pero no de unas directrices didácticas comúnmente aceptadas o recomendadas por el MCER o por el Plan Curricular del Instituto Cervantes (Instituto Cervantes, 2007).

Nuestro estudio ha confirmado las primeras dos hipótesis iniciales, según las cuales:

1) El conocimiento del código visual no muestra relación de dependencia significativa con el nivel del español.

2) Los niveles avanzados de ELE no garantizan la lectura correcta de los textos visuales en el cuestionario.

La hipótesis 3 se ha confirmado, pero en un grado de dependencia muy bajo:

3) Los alumnos que conocen la expresión idiomática dar calabazas la usarán en la interpretación del cuadro "Las calabazas".

Sin embargo, no se ha confirmado la hipótesis 4, que apuntaba a que los alumnos anglohablantes aplicarían el conocimiento del sustantivo bookworm en la interpretación de la imagen del "gusano de libros" e intentarían buscar su equivalente en español.

\section{Líneas de mejora del estudio}

Considerando los resultados obtenidos, parece conveniente ampliar la investigación no solo con representantes de más nacionalidades, sino también con hablantes nativos del español, sobre todo para comprobar el grado de aplicación del código lingüístico en combinación con el pictórico en la pregunta sobre el cuadro "Las calabazas". Quizás sea conveniente que participen en la respuesta de esta pregunta alumnos de la Facultad de Bellas Artes para obtener una segunda comparación entre nativos no expertos y nativos expertos en la materia.

Por último, creemos necesario recabar opiniones sobre qué imágenes se consideran representativas de la cultura española y elaborar una propuesta de contenidos y textos visuales para la enseñanza-aprendizaje de ELE por niveles.

\section{Conclusiones}

Las principales conclusiones del estudio apuntan a que existe un conocimiento del código visual en los niveles avanzados, pero aun así no parece ser resultado de una programación consciente, sino más bien con frecuencia parece algo arbitrario o casual, puesto que no se observó una relación de dependencia significativa entre el nivel de español y la mayoría de las variables estudiadas.

El Marco común europeo de referencia para las Lenguas (Consejo de Europa, 2002) y el Plan curricular del Instituto Cervantes (Instituto Cervantes, 2007) no contemplan una enseñanza programada por niveles de todos los códigos semióticos, tan necesarios para la competencia comunicativa y para la interacción. Por consiguiente, creemos que es necesario elaborar propuestas metodológicas y didácticas en general para otorgarle a la comunicación no verbal y a la visual, en concreto, la importancia que se merece en la enseñanza de idiomas extranjeros.

\section{Bibliografía citada}

Consejo de Europa, 2002: Marco común europeo de referencias para las Lenguas [http://cvc.cer vantes.es/ensenanza/biblioteca_ele/marco/ cvc_mer.pdf, fecha de consulta: 14 de octubre de 2013].

ECO, Umberto, 1989 [1968]: La estructura ausente. Introducción a la semiótica, Barcelona: Lumen.

Instituto Cervantes, 2007: Plan curricular del Instituto Cervantes, Madrid: Biblioteca Nueva.

Lotman, luri M., 2003 [1981]): "La semiótica de la cultura y el concepto de texto”, Entretextos. Revista Electrónica Semestral de Estudios Semióticos de la Cultura 2, 1-6. Traducción del ruso de Deside- 
rio Navarro [http://www.ugr.es/ mcaceres/entre textos/pdf/entrez/escritos/escritos2.pdf, fecha de consulta: 24 de octubre de 2013].

Lotman, luri M., 2003 [1987]: "El símbolo en el sistema de la cultura”, Entretextos. Revista Electrónica Semestral de Estudios Semióticos de la Cultura 2, 1-13. Traducción del ruso de Desiderio Navarro [http://www.ugr.es/ mcaceres/entre textos/pdf/entrez/escritos/escritos4.pdf, fecha de consulta: 21 de octubre de 2013]

NíkLEva, Dimitrinka G., 2013: "La intertextualidad entre lengua y artes en la enseñanza de idiomas", Onomázein 27, 107-120.

Poyatos, Fernando, 1994: La comunicación no verbal, Madrid: Istmo.

Verón, Eliseo, 1987: La semiosis social, Buenos Aires: Gedisa Edit.

Zecchetto, Victorino, 2002: La danza de los signos. Nociones de semiótica general, Ecuador (Quito): Abya-Yala.

\section{Anexo}

El cuestionario en su versión original para los alumnos participantes contenía más espacio para las respuestas libres.

\section{CUESTIONARIO}

\section{SOBRE EL CÓDIGO VISUAL EN ESPA-} ÑOL COMO LENGUA EXTRANJERA

1. Lengua nativa:

2. Nacionalidad:

3. Edad:

4. Sexo: masculino $\square$ femenino $\square$

5. Estudios:
6. Tu nivel de español es: $\mathrm{A} 1 \square \quad \mathrm{A} 2 \square$
$\mathrm{B} 1 \mathrm{~L}$
B2 $\square$
$\mathrm{C} 1 \mathrm{~L}$
$\mathrm{C} 2 \mathrm{\square}$
no lo sé $\square$

7. ¿Cuántos años llevas estudiando español?

8. ¿Has estudiado el español solo en tu país de origen? sí $\square$ no $\square$

9. ¿Has estado en España o en otro país de habla hispana?
a) hasta 3 meses
b) de 3 meses a 1 año
c) de 1 año a 3 años
d) más de 3 años
e) no he estado nunca en España ni en otro país de habla hispana

10. Observa el cuadro titulado "Las calabazas" de Ignacio Pinazo y formula brevemente la historia que te imaginas:

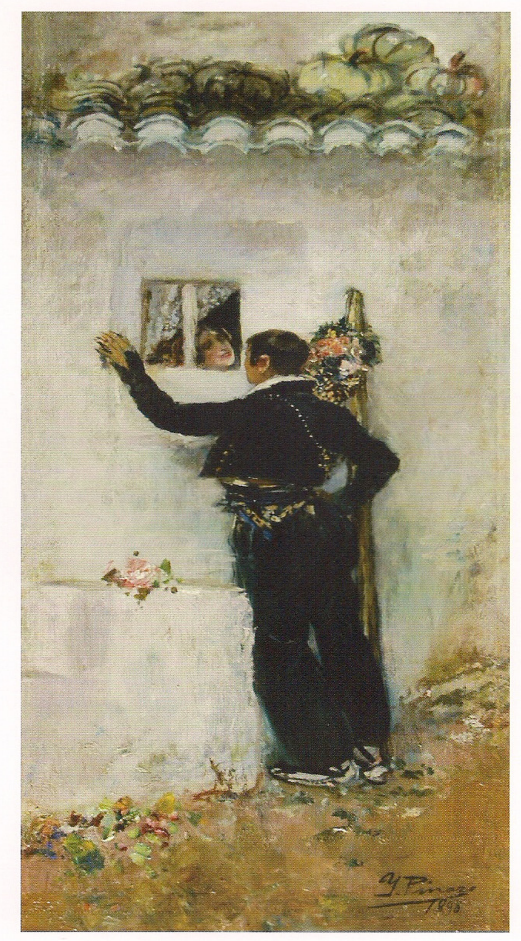


11. ¿Conoces este personaje? sí $\square$ no $\square$ ¿Qué hace el ratoncito Pérez?

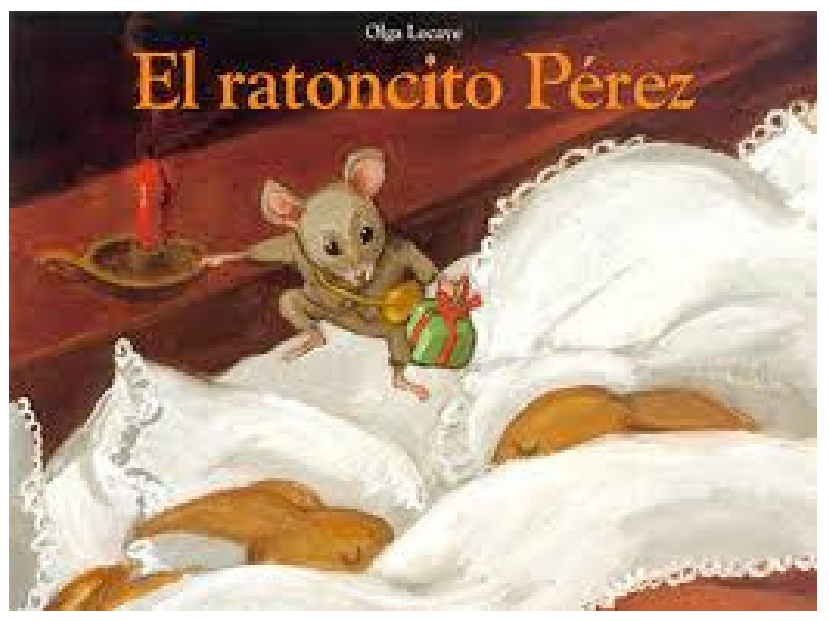

12. ¿Hay un personaje parecido en tu cultura? sí $\square \quad$ no $\square \quad$ ¿Cómo se llama?

13. ¿Adónde va el cobrador del frac?
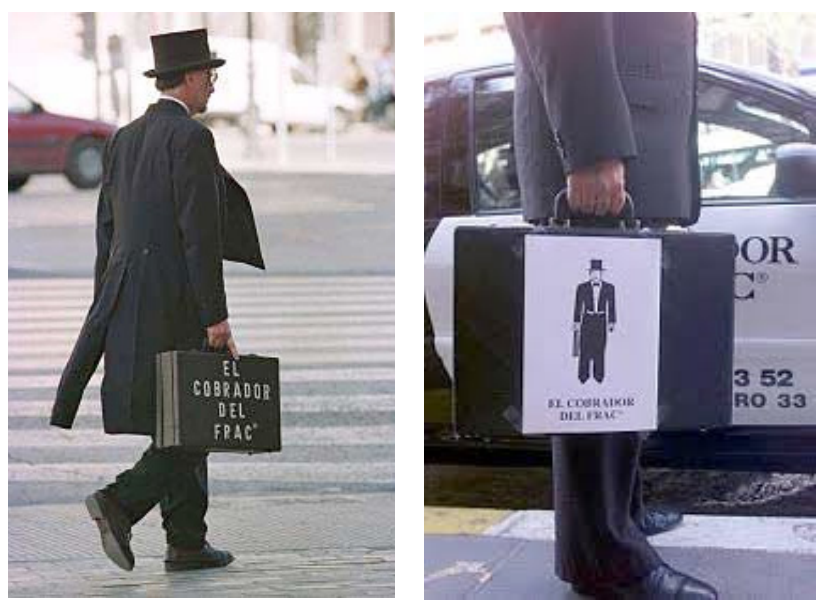
a) va a una cena
b) es un sastre y visita a sus clientes
c) visita a los morosos
d) va a un concierto
e) es acompañante
f) otro

14. ¿Conoces la expresión dar calabazas? sí $\square \quad$ no $\square$

15. Observa la siguiente dedicatoria en un libro regalado en Navidad en España.

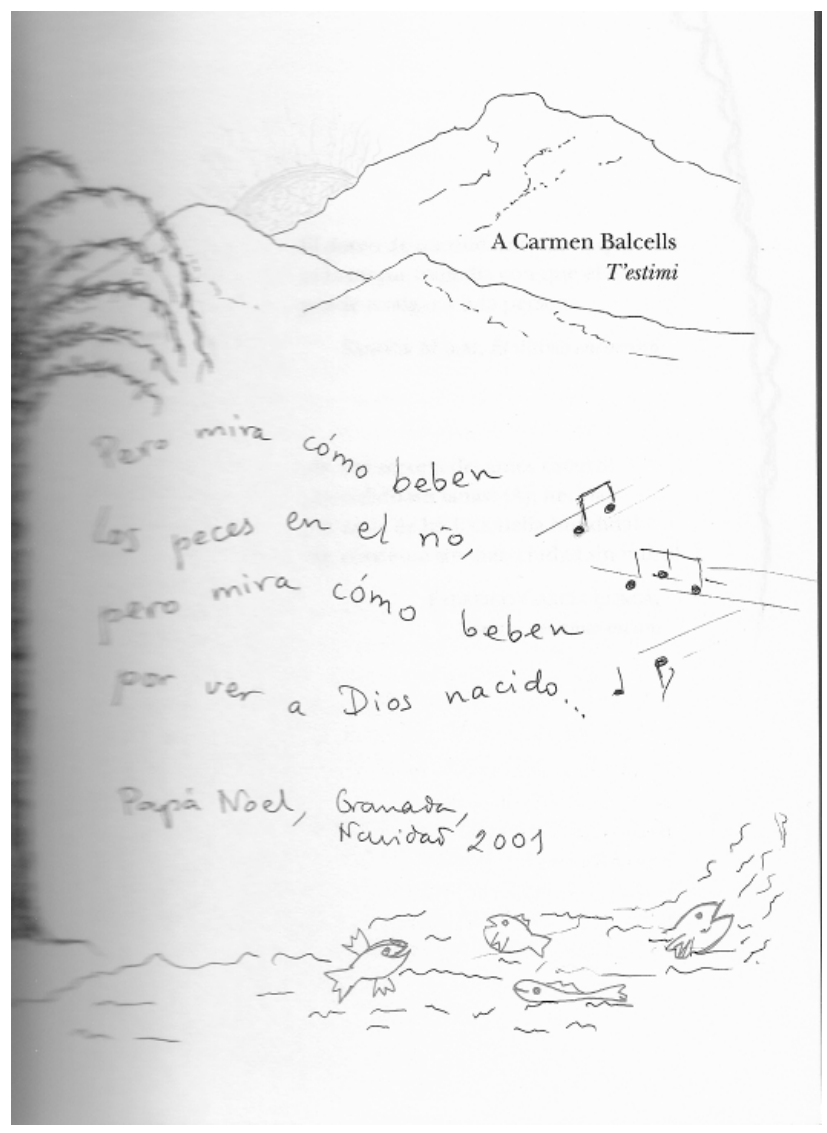

¿Crees que el autor de la dedicatoria ha sido original? ¿Por qué?

16. ¿Qué significa la expresión dar calabazas?

(Casillas que rellenará el profesor: $\vee \square \mathrm{F} \square$ ) 
17. Conoces la expresión dar calabazas por:

a) un profesor de español

b) un hablante nativo del español

c) una estancia en un país de habla hispana $\square$

d) libros

e) películas

f) otros

18. ¿Qué crees que significa la siguiente imagen? Es un gusano con gafas y un libro abierto. Está delante de una biblioteca en Manchester (Reino Unido).
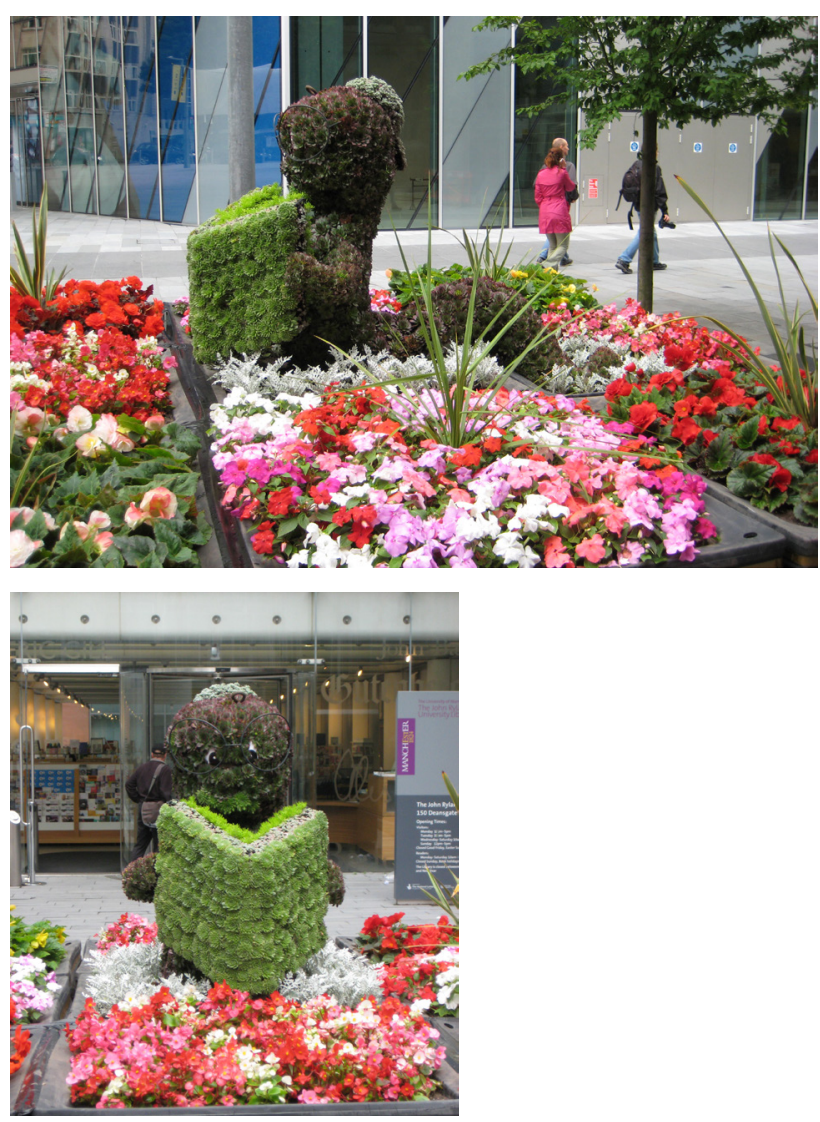

19. Usando la idea de la imagen anterior, ¿qué se podría poner delante de una biblioteca en Espaก̃a? 